\title{
O ESCRITO E O ORAL: UMA DISCUSSÃO INICIAL SOBRE OS MÉTODOS DA HIST ÓRIA
}

\author{
Antonio Vicente M arafioti Garnica*
}

"O espetáculo das atividades humanas, objeto particular da história, seduz a imaginação dos homens, principalmente quando o seu desenrolar se enfeita com as sutis seduções do que é estranho"

"N ossos demônios são deuses dos conquistados"

\begin{abstract}
Resumo: 0 artigo procura discutir os métodos utilizados pela $\mathrm{H}$ istória, apresentando argumentos que advogam pela legitimidade do aproveitamento das fontes orais, contra a hegemonia das chamadas "fontes primárias". Argumenta sobre o equívoco de julgar as fontes escritas como mais seletivas ou menos tendenciosas que as orais, justificando como fundamental para as Ciências da Educação essa nova abordagem à H istória.
\end{abstract}

Unitermos: H istória, H istória O ral, Educação Científica.

Abstract: The article tries to discuss the methods used by $\mathrm{H}$ istory, presenting arguments which advocate to the legitimacy of the use of oral sources, against the hegemony of the called "primary sources". It Argues on the mistake to judge the written sources as more selectives or less tendenci ous than the oral ones, justifying as fundamental to the Sciences of Education this new approach to the H istory.

Keywords. H istory, O ral H istory, Scientific Education.

\section{UM A INTRODUÇÃO NECESSÁRIA}

$\mathrm{N}$ ão sou historiador, sou professor de M atemática e, portanto, atrevo-me. Fui, recente e circunstancialmente, envolvido na pesquisa com $\mathrm{H}$ istória. M ais especificamente, coube a mim orientar pesquisa inscrita numa tendência que chamarei de "História da Educação M atemática Brasileira". M eu fascínio pela H istória, porém, já vem de muito tempo. M esmo a rigidez da história cronológica presente os livros didáticos me encantava. $D$ epois disso comecei a ler, quase que casual mente, os textos de C arlo Ginzburg, a partir do que perce bi uma estrutura toda nova, numa linguagem diversa daquela a que, na escola, eu estava habituado. N ovos recursos, novos tratamentos, outros textos, redobrado encanto. Por conta de minhas pesquisas sobre linguagem formal e formas alternativas de leitura a textos didáticos de Matemática, um horizonte de possibilidades para o estudo da conexão oral-escrito estava posto. A H istória O ral foi o ponto de convergência de toda essa trajetória, cujo início relato aqui.

Convidado pelo professor Sérgio N obre a discutir essas minhas compreensões sobre a historiografia e seus métodos em Seminário de Estudos no Programa de Pós-G raduação em Educação M atemática de Rio Claro, sistematizei al gumas considerações a partir do tema proposto: H istória e M emória. Percebi, ao preparar minha comunicação, que a questão da interconexão M emória/H istória é, na verdade, uma pseudo-questão que não mais se justifica no

\footnotetext{
* Professor AssistenteD outor do D epartamento de M atemática, Faculdade de Ciências, U N ESP - Câmpus de Bauru (e mail: vgarnica@bauru.unesp.br )
} 
contexto contemporâneo. D ecorreu disso a compreensão de que a questão estava deslocada, pois na realidade, as dúvidas e ansiedades eram relativas ao método e fundavam-se no plano do oral e do escrito, isto é, voltavam-se à coleta dos dados, dirigiam-se ao estudo das formas de apropriação dos fatos históricos.

M inhas considerações, naquele Seminário, foram enriquecidas pelas informações e pontos de vista dos demais componentes do debate e estão, em parte, incorporadas nesse pre sente texto².

\section{A SUPREM ACIA DO ESCRITO}

Reconheço, em princípio, a existência de duas fontes, cada uma com suas peculiaridades, de manifestação discursiva: a escrita e a oralidade.

0 próprio conceito de cultura está irremediavelmente vinculado ao surgimento da escrita, segundo Paul Ricoeur. A possibilidade do texto (e sua potencialização com o recurso da impressão) carrega, em si, por exemplo, um paradoxo entre espiritualidade e materialidade: é porque torna-se material, fixado em laudas por caracteres gráficos, que o texto espiritualizase, abre-se a leitores potenciais. A escrita, embora desfavoreça, de certo modo, o contato pessoal, a situação dialógica face a face, ganha em potencialidade e, ao contrário da evanescência dos recursos orais, permite que a situação por ela fixada possa ser retomada, desafiando 0 tempo, abrindo-se à possibilidade de ser re-vivida, tirada da letargia dos símbolos impressos, pelo mudo diálogo autor/leitor.

A escrita foi, sem dúvida, uma conquista fundamental do humano e tornou-se, ideologicamente, um poder a ser disputado, temido, assegurado. A desconfiança do verbal, a necessidade de rigorosos contratos escritos nas diversas instâncias da vida cotidiana atual, as dificuldades de acesso à divulgação pela "imprensa de massa" são sinais, dentre os muitos, desse privilégio, dessa segurança que nos transmite o documento escrito formalmente posto ${ }^{3}$. Essa concepção, essa importância desmedida atribuída ao escrito, que não poucas vezes relega ao folclórico e ao mítico outras fontes de apreensão da realidade, pode ser constatada historicamente. Tanto quanto ocorreu à medida (a afirmação "a medida é importante" parece ter sido ideologicamente desviada para "só é importante o que pode ser medido", do que nos alerta Abrahan M oles), a escrita passa a ser critério para se estabelecer hierarquia de importâncias e, até mesmo, pressuposto para a existência. A hegemonia da escrita só encontrará resistência na prepotência do fogo ${ }^{4}$ ?

\footnotetext{
2 Agradeço a Romélia M ara Alves Souto por sua discussão sobre esse meu artigo. Algumas de suas sempre pertinentes considerações foram nele incluídas.

3 Esse fascínio pelo documento escrito parece desconsiderar o viés nitidamente ideológico da seleção imposta pelo poder da mídia. É nesse sentido que pretendemos caminhar nesse artigo.

4 Sabemos de culturas latino-americanas cujos documentos foram sumariamente eliminados pelos espanhóis. E não só os documentos escritos: considerados objetos demoníacos, praticamente todos os kipus - interessante instrumento mnemônico do Peru incaico, utilizado para cálculos e, inclusive, para registros históricos - foram destruídos pelos espanhóis. M as a tentativa de dominação pela eliminação de registros escritos, obviamente, não é prerrogativa de al gumas culturas de colonização espanhola. Fora desse contexto, lembramos da destruição da
} 
A ciência da H istória, por sua vez, nesse contexto, acaba por considerar legítimos somente os estudos realizados a partir de materiais escritos, as chamadas "fontes primárias".

Partindo dessas considerações e munido de material bibliográfico pertinente, dediquei-me a procurar exemplos para contra-argumentar sobre essa supremacia do escrito como única possibilidade de fundamentação aos estudos históricos. Em meu horizonte, porém, nunca esteve sequer a possibilidade de negar importância à escrita (o que seria desastroso), mas talvez tenha sido necessário optar por apresentar exemplos de natureza "radical", com a intenção de explicitar claramente as lacunas do discurso clássico da pesquisa na área. Visando ao estabelecimento da $\mathrm{H}$ istória $\mathrm{O}$ ral como recurso legítimo, importante e meritório dentre as atuais abordagens à $\mathrm{H}$ istória contemporânea, foi proposital esse desequilíbrio, numa atitude similar àquela que, não sem discordâncias, foi chamada por um educador de "teoria da curvatura da vara".

\section{FONTES PRIMÁRIAS, MEM ÓRIA E HISTÓRIA}

Fontes primárias: essa a principal das preocupações relativas à metodologia da H istória, ao menos no que diz respeito aos historiadores chamados clássicos ou documentalistas. "Produção escrita" é sinônimo impreciso - mas certamente não equivocado - da expressão "fontes primárias". A imprecisão da linguagem falada, a plurivocidade e o inevitável apoio à subjetividade no tratamento da memória coletiva são certamente os maiores - senão únicos - argumentos contrários ao fascínio que a oralidade tem contemporaneamente exercido nos historiadores preocupados com posições metodológicas. M esmo relativizando a afirmação mais radical (e mais comum), num exercício de tolerância bem calculado, incorrem no erro da suposição - que tentaremos mostrar ser infundada - de que as fontes escritas são menos seletivas ou menos tendenciosas que as fontes orais. Também confundem-se as estações quando se utiliza o termo "memória" em oposição à "história", impropriedade muito comum na retórica disposta a descredenciar - quando não desqualificar - a abordagem histórica via 0 exame de relatos orais.

A relação "M emória/H istória" é, segundo penso, uma pseudo-questão, já há muito dissolvida, expurgada tanto do discurso dos historicistas mais clássicos quanto do daqueles envolvidos, por exemplo, com a História $\mathrm{N}$ ova. $\mathrm{H}$ á, sim, um radical gerador dessa polêmica agora ultrapassada: a divinização da memória, como nos mostram Le G off e Vernant. O s gre gos fizeram da memória sua deusa $\mathrm{M}$ nemosine e a poesia, ato originariamente criador, foi com ela identificada. Revelando aos poetas os segredos do passado, M nemosine os introduzia nos mistérios do além. Embaladas no berço da oralidade, a poesia e a memória começam sua trajetória concebidas como um dom para iniciados, sendo a reminiscência uma técnica ascética e mística. Com os pitagóricos essas crenças aliam-se à já conhecida doutrina de reencarnação das almas. N isso, a "colocação da memória fora do tempo separa, radicalmente, a memória da história". Esse "desequilíbrio dos mitos da memória", porém, é ultrapassado, na trajetória dos tempos, gerando uma proposta de harmonia percebida e sintetizada de modo muito claro por

Biblioteca de Alexandria pelos cristãos. Um exemplo que talvez nos seja mais próximo e familiar é o da queima das escrituras sobre a escravatura no Brasil, motivada por interesses político-econômicos e empreendida por Rui Barbosa. 
Jacques Le G off: "A memória, onde cresce a história, que por sua vez a alimenta, procura salvar o passado para servir o presente e o futuro". Para os contrários ou reticentes em relação aos adeptos da $\mathrm{H}$ istória das Mentalidades, argumento com Toynbee, que busca, também ele, na memória, na reminiscência, insights para a constituição de suas hipóteses, com o que os fatos históricos ${ }^{5}$ ganham vida. Há certamente, uma preocupação exaustiva com fatos e hipóteses, mas servirão a nossas argumentações as afirmações de Toynbee quanto à origem e/ ou ancoramento dessas hipóteses.

"O s versos de Browning /.../ começaram a repetir-se em minha mente, e num vislumbre ocorreu-me que o Império Britânico talvez estivesse /.../ dirigindo-se para o mesmo destino do Império Veneziano. Naquele momento, esse pensamento me passou pela mente, pois em 1912, o Império Britânico parecia estar no zênite. Eu tinha uma recordação viva do jubileu de diamante da Rainha Vitória em 1897, quando eu era um menino impressionável de oito anos de idade /.../. /.../ devido ao acidente pessoal da longevidade, vivi até ver o Império Britânico liqüidado /.../".

Assim, ultrapassada essa pseudo-questão, voltamos à proposta de argumentar sobre o equívoco de julgar as fontes escritas como mais seletivas ou menos tendenciosas que as orais, essa, sim, uma questão fundamental do atual debate.

\section{ALGUN S EXEM PLOS: FERM ENTOS PARA UMA CRÍTICA}

Alguns poucos exemplos, são, segundo penso, decisivos para advogar sobre as credenciais de qualidade, necessidade e legitimidade negadas às fontes orais e estabelecêlas como instrumento privilegiado para a recuperação e a (re)interpretação de fatos históricos ${ }^{6}$. Alguns desses exem plos referem-se a adulterações propositais de registros, ideológica e historicamente reconhecidas, impostas pelo poder dominante; outros referem-se a construções textuais tendenciosas, geradas a partir de valores específicos, estéticos ou morais.

D o primeiro grupo, isto é, dos exemplos acerca das adulterações propositais, impossível não lembrar da damnatio memoriae, a lei instituída pelo senado romano que possibilitava fazer desaparecer o nome do imperador defunto e de seus circundantes dos documentos e inscrições monumentais.

\footnotetext{
5 “O pressuposto comum do historiador de que 'os fatos estão aí para serem usados' é, sem dúvida al guma, errado. 0 s fatos não são, na realidade, como rochedos que foram destacados, modelados e depositados exclusivamente para serem manipulados /.../. O s fatos são como rochas lascadas e britadas, como pedras rachadas ou tijolos. A ação humana conseguiu fazer deles o que são, e eles não seriam o que são se isso não tivesse ocorrido. 0 s fatos da história não são coisas brutas ou eventos alheios à mente, pois já foram filtrados antes que deles eu tivesse conhecimento. /.../. O s fatos não podem tomar vida sem os bons ofícios de uma hipótese". (TOYN BEE, 1987)

6 C ertamente há, nesse caso, severos limitantes. Segundo os defensores do que se chama, atualmente, $\mathrm{H}$ istória 0 ral (do que trataremos oportunamente), 0 apoio do depoimento falado servirá para o historiador contemporâneo em seu trabalho voltado aos fatos ocorridos após a década de 1930. A lucidez dos depoentes, entretanto, poderá ampliar ou diminuir esse espectro cronológico. Esses e outros redimensionamentos dependerão de fatores vários, estabelecidos por rigorosos parâmetros ainda sob apreciação.
} 
Essa manipulação da memória escrita é também extremamente visível nas decorrências do Terror. Como se sabe, a Revolução Francesa não se limita ao ano de 1789, marco devido à tomada da Bastilha. 0 explosivo coquetel composto com desigualdades sociais, privilégios de uma nobreza desregrada, corrupção política, conveniente indiferença do clero, condições quase feudais a que eram submetidos os trabalhadores (especialmente os do campo) e pressupostos iluministas, foi sendo lentamente detonado no que se chamou "O Grande Terror". Essa situação de conflitos foi habilmente descrita por Robert Darnton, n'O Beijo de Lamourette, de 19897. N essa época em que cumpria à guilhotina uma democratização na morte, quando os matadores públicos ficavam no meio da cidade, e filósofos auxiliados por "panfletistas profissionais", acendendo as chamas das Luzes, "conseguiram empanar a aura sagrada da coroa", houve uma das mais marcantes iniciativas de manipulação da memória, segundo Le G off: "D epois do 9 Termidor ${ }^{8}$ ése sensível aos massacres e às execuções do Terror, decidindo-se [deliberadamente] subtrair à memória coletiva [principalmente em seus registros escritos] a multiplicidade das vítimas".

Já num segundo grupo de exemplos - de natureza complementar e de forma alguma divergente do anterior -, colocam-se as construções textuais plasmadas em concepções particulares, uma manipulação nem sempre estudada, projetada, pré-arquitetada, mas que, de qualquer forma, se insinua ora pelas lacunas discursivas, ora pelo excesso de empenho para a atribuição de significado específico. D esse grupo apresento um excerto dos Anais de São G all, do século VIII, conforme citado por O Ison e Torrance.
“709. Inverno rigoroso. Faleceu o D uque G ottfried.
710. Ano difícil. Colheitas insuficientes.
712. Inundações por toda parte
714. M orre Pippin, administrador do palácio.
718. Carlos dizimou os saxões.
721. T heudo expulsou os sarracenos da Aquitânia.
725. O s sarracenos ressurgem
731. M orre o presbítero Bede, o Venerável.
/... "

$\mathrm{N}$ ão é clara, aí, a lacunaridade do discurso? Pode-se afirmar que nada ocorreu nos anos não citados ou que, nesses anos, tudo o que ocorreu deu-se segundo o olhar de São Gall? Por ser documento escrito, fonte primária, a aceitação deve dar-se sem resistências? Q ual sin-

\footnotetext{
7 “/.../ a desmontagem do quadro mental do Antigo Regime demandou violência, e/.../ temos a dificuldade em imaginar a própria violência, esse tipo de violência iconoclasta, destruidora do mundo, revolucionária. É verdade que vemos os assaltos e acidentes de trânsito como fatos corriqueiros. $M$ as, em comparação a nossos antepassados, nós vivemos num mundo onde a violência foi retirada de nossa experiência cotidiana. O s parisienses viviam passando por cadáveres pescados à margem do Sena e pendurados pelos pés ao longo da margem. Sabiam que uma mine patibulaire ('cara patibular') era um rosto parecido com uma daquelas cabeças degoladas e expostas pelo carrasco público na ponta de um forcado. Tinham presenciado esquartejamentos de criminosos em execuções públicas. E não podiam andar pelo centro da cidade sem empapar os sapatos de sangue

8 Como sabemos, às mudanças almejadas pelo governo revolucionário seguiram-se alterações na configuração do calendário, instituindo-se o calendário revolucionário, com a extinção de al guns feriados e a criação de outros, além de ter sido colocada em vigência um novo sistema de contagem para os dias e uma nomenclatura própria para os meses. Em nosso atual sistema, 09 Termidor é equivalente ao dia 27 de julho, décimo primeiro mês do "novo calendário". N esse dia a convenção decide a prisão de Robespierre. Robespierre, Saint-Just, C outhon e mais dezenove dos seus são guilhotinados em 10 Termidor. M ais setenta e dois jacobinos têm o mesmo destino no dia seguinte.
} 
gularidade torna esse registro escrito mais legítimo que um discurso oral para a história contemporânea? A figura do presbítero Bede e a clara vinculação do escritor-santo com a Igreja não indicam um ponto de vista, no mínimo, tributário de concepções religiosas? A familiaridade com a movimentação do palácio, seus duques e administradores, não indica um viés político que não pode ser negligenciado?

Disso, um novo e significativo capítulo sobre os tributos que a documentação escrita presta às esferas política e religiosa precisa ser esboçado. Com o aparecimento da escrita ocorre uma profunda transformação da memória coletiva, cristianizada durante a idade média (principalmente no culto à memória dos mortos e dos santos). Ainda nesse período histórico, o escrito desenvolve-se a par com o oral, embora possa ser já constatado o germe de uma intensificação na utilização do escrito como suporte da memória. $\mathrm{N}$ a Renascença, a imprensa revoluciona a memória ocidental, sendo os dicionários (que atingirão a dimensão das enciclopé dias) do século XVIII uma clara conseqüência dessa potencialização da escrita. Entre fluxos e refluxos na história da memória", constata-se que o verdadeiro ressurgimento da arte da memória vem acompanhado pela literatura, no Romantismo. Segundo Le Goff, o furor comemorativo torna-se, à essa época, epidêmico e as festas e comemorações, desde há muito laicizadas, tornam-se instrumento de governo. Segue-se uma nova vaga de estatuária (a memória petrificada) e uma "nova civilização da inscrição", ao mesmo tempo em que se acelera o movimento científico. N esse contexto surgem os museus públicos e os grandes arquivos nacionais ligados ao poder político e ao clero. Recente artigo da Folha de São Paulo, sobre a sistematização dos arquivos públicos hoje disponíveis na cidade de São Paulo, nos mostra de forma inequívoca essa articulação entre "poderes" e documentação escrita"a

$$
\text { NOVAS HISTÓRIAS: UM ALENTO À ORALIDADE }
$$

Assegurar que "fontes primárias" não são, como se poderia supor, acima de qualquer suspeita levanta a questão sobre quais instrumentos seriam legítimos fundantes para a pesquisa histórica. Certamente os exemplos aos quais fiz referência são radicais nesse intuito de rela-

\footnotetext{
9 Embora esse parênteses tenha o objetivo de argumentar sobre o forte vínculo (ideológico) da escrita com interesses políticos e religiosos (no que, obviamente, também a fala exerce com extrema propriedade seu papel), cabe ressaltar que a trajetória da dualidade oral/escrito e sua relação com a memória coletiva é extremamente mais rica e dificilmente pode ser tratada linearmente. $\mathrm{H}$ á períodos intercalados de harmonia e severos conflitos entre 0 escrito e o oral, do mesmo modo como há, em determinadas épocas e contextos culturais, ocasos e ressurgimentos em relação a uma preocupação com a memória. U m bom exemplo disso é o culto à memória dos mortos. Na idade das Luzes, ao passo em que a memória coletiva parece insinuar seu reaparecimento (depois de tornada marginal e condenada pela Igreja, por volta do século XVI, dada sua ligação com o ocultismo) a memória funerária, representada principalmente pela comemoração do dia de finados e pelas inscrições tumulares, entra em crise. Parece se almejar uma eliminação da morte, o que o Romantismo tratará de reverter pelo ressurgimento da "atração pelo cemitério, ligada a memória". 0 túmulo separado da igreja volta a ser o centro da lembrança, parte essencial do ritual de visita aos defuntos. A comemoração dos finados, porém, foi instituída no século IX, e caiu lentamente em esquecimento. No século XII, a necessidade de se intensificar o esforço dos vivos em favor de seus falecidos queridos exige a criação de um terceiro lugar no Além, o purgatório, meio termo entre paraíso e inferno, do qual mais rápido a memória do defunto livrava-se quanto maiores fossem os esforços (facilmente quantificáveis) de seus parentes vivos.

10 Segundo 0 artigo são os seguintes os primeiros arquivos constituídos (mas não necessariamente abertos ao público) na cidade de São Paulo: (1560) Câmara Municipal e Irmandade da Santa Casa de Misericórdia; (1594) Venerável $O$ rdem Terceira de N. Sra. do M onte do C armo; (1640) O rdem dos Frades M enores;(1641) Venerável O rdem Terceira de São Francisco da Penitência; (1685) O rdem das Carmelitas D escalças; (1695) Irmandade do
} 
tivizar a importância dada aos documentos escritos, e reforçam minha intenção de considerar outras possíveis fontes de acesso aos fatos. Além disso, parece ingênuo acreditar que as escrituras nos dariam acesso à história "verdadeira". A existência de tal história, obviamente, está ligada aos créditos de legitimidade dados às fontes escritas e é, ela também, uma suposição equivocada. M uito já foi falado sobre a história dos vencedores como hegemônica e sobre o decorrente esquecimento da história de minorias. D e um ponto de vista filosófico, não há um significado aprioristicamente ligado às coisas e, portanto, também os fatos históricos não têm, por si próprios, um significado que lhes seja peculiar, unívoco. 0 s significados atribuídos aos fatos são filtrados por aqueles a quem cumpre o estabelecimento de determinados elementos da história (os historiadores, por exemplo) num processo cíclico e interminável de interpretações e compreensões. Sendo uma ilusão essa história "verdadeira", caracterizo a H istória, na esteira de alguns pensadores, como sendo o conjunto de esforços que objetiva essa quimera, mas que a reconhece como tal. Essa posição, que assume o caráter ideológico dessa produção social, certamente, traz certas implicações para o método histórico (ou a metodologia da história) e, conseqüentemente, para o grupo social responsável pela produção e divulgação desse conhecimento. E surgem novas histórias. Segundo Robert D arnton:

"As variedades mais instigantes e inovadoras da história são as que tentam escavar sob os fatos, para descobrir a condição humana tal como foi vivida por nossos antepassados. Essas variedades podem receber vários nomes: história das mentalidades, história social das idéias, história etnográfica ou apenas história culturas /.../ Seja qual for o rótulo, porém, a pretensão é a mesma: entender o sentido da vida, não numa vã tentativa de dar respostas últimas aos grandes enigmas filosóficos, mas oferecendo um acesso a respostas dadas pelos outros, tanto nas rotinas diárias de suas vidas quanto na organização formal de suas idéias /.../"

São muito conhecidos, nesse panorama das "novas histórias", os trabalhos do italiano Carlo Ginzburg ( 0 queijo e os vermes. 0 cotidiano e as idéias de um moleiro perseguido pela Inquisição; H istória N oturna: decifrando o sabá) e dos franceses Jacques Le G off, Philippe Ariés e G eorges D uby (os doisúltimos foram os organizadores do magnífico H isória da vida privada, por exemplo) dentre outros tantos nomes de estudiosos dedicados a essas tendências historiográficas atuais. N ovas abordagens à história, porém, exigem esforços de alteração também no quadro metodológico. $O$ que hoje se conhece por H istória O ral, viés aceito pelos novos historiadores mas ainda, compreensivelmente, visto com reservas pelos documentalistas, surge nesse contexto, colocando-se como uma possibilidade para estudos em história contemporânea. Alguns autores atribuem singular importância às fontes orais dado seu caráter involuntário, permitindo "estruturas de compreensão alternativas às elaboradas a partir do trabalho exclusivo com fontes escritas". As disfunções entre depoimentos, argumentações constantes daqueles que optam pelo documentalismo, só fazem realçar a impropriedade do mito da história verdadeira, da versão definitiva, do depoimento exato. Essas divergências discursivas possibilitam, de modo dinâmico, que os viéses ideológicos sejam percebidos e analisados e que as várias per-

Santíssimo Sacramento da Catedral de São Paulo; (1711) Irmandade de N . Sra. do Rosário dos H omens Pretos; (1720) Arquivo do Estado de São Paulo; (1722) Confraria de N. Sra. dos Remédios; (1728) Venerável Irmandade de N. Sra. da Boa M orte; (1742) Segundo Cartório de N otas; (1762) Venerável Irmandade de São Pedro dos Clérigos; (1774) O rdem da Imaculada Conceição e (1778) Primeiro C artório de N otas. 
cepções acerca do mesmo contexto histórico sejam levadas em consideração, sejam elas complementares ou rivais.

A H istória O ral surge, nos Estados U nidos, em 1947, e chega ao Brasil em meados de 1970. Realizado segundo os parâmetros propostos para essa modalidade de trabalho histórico, talvez o texto brasileiro mais conhecido seja o M emória e Sociedade: Iembranças de velhos, de Ecléa Bosi, que alcançou rápida repercussão nacional, embora haja outros bons trabalhos acadêmicos desenvolvidos nesse mesmo enfoque. Talvez pela novidade da proposta a $\mathrm{H}$ istória $\mathrm{O}$ ral ainda esteja enfrentando o debate sobre certas questões. Concebida como um recurso para o levantamento (histórico) da vida social discute-se, ainda, se essa possibilidade de aproveitamento da oralidade é uma técnica, uma disciplina ou uma metodologia.

O s que a defendem como técnica argumentam que

"A H istória O ral não passa de um conjunto de procedimentos técnicos para a utilização do gravador em pesquisa e para posterior conservação das fitas; / .../ não possui fundamentos filosóficos da teoria, nem procedimentos que possam ser qualificados como metodológicos"

O utros, por sua vez, afirmam que

"A H istória O ral inaugurou técnicas específicas de pesquisa, procedimentos metodológicos singulares e um conjunto próprio de conceitos. Pensar a $\mathrm{H}$ istória O ral dissociada da teoria é o mesmo que conceber qualquer tipo de história como um conjunto de técnicas, incapaz de refletir sobre si mesma. $\mathrm{N}$ ão só a H istória O ral é teórica, como constituiu um corpus teórico distinto, diretamente relacionado às suas práticas"

E outros, ainda, num meio termo bem calculado, julgam que

"A H istória O ral, como todas as metodologias, apenas estabelece e ordena procedimentos de trabalho, /.../ funcionando como ponte entre teoria e prática".

$N$ ão é minha intenção - pelo menos não nesse artigo - esmiuçar essas posições. Com a cautela que esse início exige, tentei apresentar elementos que pudessem advogar pela legitimidade do aproveitamento das fontes orais, contra a hegemonia das chamadas "fontes primárias". Essa opção pela história oral pode ser feita, segundo os especialistas, para o estudo de situações e contextos contemporâneos, ocorridos a partir da década de 1930, embora sejam conhecidos, nessa abordagem, estudos sobre os modelos educacionais vigentes em 1920. A lucidez e o estado de saúde dos depoentes são elementos fundamentais para essa delimitação temporal.

Poder-seia, finalmente, justificar por que reputo como fundamental para as Ciências da Educação (e, particularmente para a Educação M atemática, minha área específica de atuação) essa nova abordagem à $\mathrm{H}$ istória. Porém, também isso ficará aguardando um próximo artigo. 


\section{Referências Bibliográficas}

ABEN SO UR, M . et allii.. Tempo e H istória. São Paulo: Cia das Letras, 1992.

ARIĖS, P. eDUBY, G. (orgs.). H istória da vida privada. 5 v. São Paulo: Cia das Letras, 1991.

BOSI, E.. M emória e sociedade: lembranças de velhos. São Paulo: Cia das Letras, 1994. DARN TO N , R.. O beijo de Lamourette: mídia, cultura e revolução. São Paulo: Cia das Letras, 1990.

FERREIRA, M. de M. e AM AD O, J. (org.). U sos e Abusos da H istória O ral. Rio de Janeiro: G etúlio Vargas, 1996.

ENCICLOPEDIA EINAUDI, vol. 1. Memória-História. Lisboa: Imprensa N acional/C asa da M oeda, 1997.

GIN ZBURG, C.. H istória Noturna: decifrando o sabá. São Paulo: Cia das Letras, 1991.

GIN ZBURG, C.. 0 queijo e os vermes: o cotidiano e as idéas de um moleiro perseguido pela Inquis ção. São Paulo: Cia das Letras, 1987.

LE GOFF, J.. H istória e M emória. Campinas: Unicamp, 1996.

M EIHY, J.C.S.B.. M anual de H istória O ral. São Paulo: Loyola, 1996.

MONTENEGRO, A.T.. H istória Oral e Memória: a cultura popular revisitada. São Paulo: Contexto, 1994.

M ORAES, M. de. (org.). H istória O ral. Rio de Janeiro: Diadorim, 1994. OLSO N, D.R. eTORAN CE, N .. Cultura Escrita e O ralidade. São Paulo: Ática, 1995. TOYN BEE, A.. Um estudo da História. São Paulo/Brasília: Martins Fontes/U NB, 1987. 